\title{
The Design of a Reconfigurable Assembly System Testbed for Teaching Man- ufacturing System Design
}

\section{Dr. April M. Bryan, Western Washington University}

Dr. April Bryan is an Assistant Professor at Western Washington University. Her areas of expertise are product design and development, design optimization, manufacturing systems, and concurrent engineering. She currently teaches courses in drawing and graphics, manufacturing, engineering design, and mechanics.

Dr. Bryan received a Ph.D. and MSc. degrees in Mechanical Engineering from the University of Michigan, Ann Arbor in 2004 and 2008 respectively. She is also a 2000 alumna of Tuskegee University, where she obtained her B.Sc. degree in Aerospace Science Engineering.

Dr. Bryan gained industrial experience at John Deere where she worked as a Design Engineer from 2000 - 2002. .She has also held academic positions at Rose-Hulman Institute of Technology and the University of the West Indies, St. Augustine Campus.

\section{Dr. John Andrew Lund, Western Washington University}

Dr. Lund's research involves the development of novel control systems, sensing and measurement tools for unique environments. His previous and ongoing research efforts include the development of a highresolution wireless instrumented mouthguard for the assessment of severity of head impacts, development of an ultra-long lifespan wireless sensor devices designed to form robust data networks in remote areas lacking infrastructure, and the development of of an electron-tunneling spectroscopy based microscope control system for molecular analysis. 


\title{
The Design of a Reconfigurable Manufacturing System Testbed for Teaching Manufacturing System Design
}

\begin{abstract}
The development of a manufacturing system testbed based on the principles of reconfigurable manufacturing systems (RMS) provides an opportunity for teaching the practical side of manufacturing systems, while overcoming the challenges of high equipment start-up costs and rapid obsolescence of technology. As a result of its focus on design around a product family, a RMS is typically modular, adaptable and scalable. These characteristics make a RMS attractive for use in manufacturing systems courses as it allows faculty the ability to start with a manufacturing system that is affordable, and then to change the system as additional resources become available or as technology changes. In addition, a truly reconfigurable manufacturing system provides opportunities for students in different project groups, within a given course, to demonstrate the implementation of theoretical system designs on a single manufacturing system.

This paper presents the design and development of the Western Reconfigurable Manufacturing System Testbed (WeRMST), which was developed using the principles of reconfigurable manufacturing. The WeRMST was developed to support the teaching of a future course in manufacturing systems. The paper includes a description of the product family of lamps that the WeRMST was developed to produce and illustrates how the WeRMST could easily be adapted to produce other product families. When implemented, the proposed manufacturing system is expected to positively impact student engagement, retention, and motivation.
\end{abstract}

\section{Introduction}

A course in manufacturing systems is being proposed with the objective of providing students with the tools necessary to analyze and design manufacturing systems. The course assumes that the designs of products are already known and considers the operations and systems that are required to manufacture the product. The proposed course will cover topics on: (1) Methods for representing products such as liaison diagrams and precedence diagrams, (2) The arrangement and configuration of workstations using techniques such as line balancing and productivity analyses, (3) Assessment of the quality of manufactured products and (4) Special topics such as design for variety, concurrent engineering, and lean manufacturing.

Experience has shown that while courses such as the one proposed in this paper are useful for giving students a general introduction to the theoretical considerations involved in the design of manufacturing systems, many students enrolled in such courses are often challenged to make the connection between the tools and techniques taught, and the practice of manufacturing in real factories $^{1-2}$. The topics often remain abstract, and are considered as merely interesting academic exercises. Part of the reason for this is students' lack of experience with real manufacturing environments. As a result, many educators of manufacturing system courses share the same viewpoint as educators in other fields of engineering, i.e., in order to prepare students for industry and/or advanced studies in engineering, it is necessary to employ techniques that assist them with bridging the gap between engineering theory and practice ${ }^{1-6}$. While it has been 
acknowledged that the use of physical laboratories would be useful for this purpose, many have cited high start-up and maintenance costs, space limitations, and rapid obsolescence of equipment as barriers to implementing such systems ${ }^{2,6-8}$. The use of simulations ${ }^{2}$, collaborative industrial projects ${ }^{8}$, and virtual remote laboratories ${ }^{7}$ have therefore been proposed as alternative strategies for bringing the theory taught in manufacturing system courses into closer alignment with the way manufacturing system development is practiced in industry.

Simulations have been found to be an effective approach for reinforcing the theory of manufacturing systems design as they allow for the quick development and testing of alternative scenarios $^{2}$. Simulation software packages are often much cheaper than the hardware required for building physical manufacturing systems and the use of simulations carry no physical space requirements. Educators who have used simulations have reported that, in addition to deepening the theoretical understanding of students, simulations have resulted in deepening students' appreciation for the various roles of manufacturing engineering professionals, and have assisted students with developing professional skills such as teamwork ${ }^{2}$. However, while better than purely analytical designs, simulations still tend to be abstract ${ }^{6}$, and limited in scope. These issues are due to the fact that the allowable experiments are often limited to the functionalities built into software tools. In addition, the focus on the product is often lost when mathematically based manufacturing system design simulation models are used.

Others have found that collaborative projects with industry are a useful means for bridging the gap that exists between the theory of manufacturing systems design and the manufacture of products in factories ${ }^{8}$. In such projects, students apply the theories taught in class to solve a project that is proposed by industrial collaborators. During such courses, students may have opportunities to visit factories and/or to hold meetings with industrial representatives. When employed effectively, this approach has proven to be useful for improving students' motivation in manufacturing system courses, their appreciation for the challenges faced when applying theoretical concepts to real factory environments, their technical skills and creativity, and their soft skills such as communication, teamwork, and leadership ${ }^{1,8}$. However, due to the lack of surrounding industries, or relationships with industrial professionals, many educators do not have opportunities to build such collaborations. In addition, industrial projects are rarely well defined, and finding meaningful student projects, with sufficient didactic content, can be challenging 8 . Other barriers often experienced are the complexity involved in making arrangements to meet with industrial collaborators, and confidentiality issues that limit students' exposure to the factory or the amount of useful information that could be obtained from industrial collaborators.

While little has been reported on the use of virtual remote laboratories for teaching manufacturing systems courses, they have been used successfully for teaching a closely related subject, Robotics and Automation ${ }^{7}$. Those using this approach have found that the main benefit of such labs is that they allow students to visualize and experiment with the theories learned in class. However, as students work on virtual remote laboratory projects through computer interfaces, the sole use of this approach has been reported to lead to feelings of isolation and to decreases in student motivation ${ }^{7}$.

It is apparent that if the challenges of development and maintenance costs can be overcome, the use of physical manufacturing systems laboratories can be an effective approach for teaching manufacturing systems courses ${ }^{1,5-7}$. Labs based on physical systems allow instructors greater 
control over the theoretical focus of co-curricular activities than simulations and industrial projects. They can also serve as platforms for open discussion and the exchange of ideas between students and instructors. Furthermore, physical labs allow for greater flexibility in work schedules. All of these benefits can be obtained without the loss of the benefits of that are typically experienced with industrial collaborations ${ }^{5}$. In addition, studies have shown that such labs have the potential to improve student motivation and retention in manufacturing engineering $^{1-2}$. However, as have been mentioned, many of the currently available, off-the-shelf physical manufacturing system laboratories are quite expensive and fairly rigid. They are typically useful for performing a fixed set of experiments of limited scope and tend to be discipline focused.

This paper presents the design of an assembly system testbed, known as the Western Reconfigurable Manufacturing System Testbed (WeRMST), which was developed to support the teaching of a course in manufacturing systems. The six principles of reconfigurable manufacturing systems (RMS): scalability, convertibility, adaptability, reconfigurability, customization, and diagnosability ${ }^{9}$, along with concurrent product family and manufacturing system design principles ${ }^{10-11}$ were used to guide the for development of the WeRMST. Therefore, the WeRMST has the flexibility to be used for a wide range of lab courses and student projects. The inherent reconfigurability of the WeRMST means that the system can be developed within a limited budget and space, but can be easily converted or scaled as additional funds become available, class sizes increase, or as technology changes.

The development of the WeRMST began with elaboration of the architecture of the product family $(\mathrm{APF})^{12}$. This was followed by the use of mixed model assembly line balancing and concurrent design of product family and assembly system design techniques ${ }^{10-11,13}$ to determine the number and layout of workstations in the system. The final phase of the development process involved the design of the WeRMST's electronics and controls systems. This proposed RMS is a practical and cost effective approach for building physical manufacturing systems that can be adopted by almost any institution.

\section{Development of the Western Reconfigurable Manufacturing System}

The WeRMST was developed over a period of eight months by a team of five undergraduate students and one faculty member. Three of the undergraduate student researchers worked on the project part-time over the period of two quarters as part of a work study project. Four students, two of which were continuing students, worked on the project full time during one summer as part of a summer research program.

A hybrid product development and manufacturing system design approach was utilized for the development of the WeRMST ${ }^{10-11}$ as shown in Fig. 1. The first stage in the development of the WeRMST involved project definition, during which the objectives of the WeRMST were clarified and the plans were made for developing the system. This was followed by the establishment of the system requirements. As the WeRMST was to be developed using the principles of RMS, it had to be capable of producing a product family. However, the objective of the project was the development of the WeRMST, not the product family. Therefore, the design specifications were concentrated on the WeRMST. After establishment of the design 
requirements, there was a need to determine whether a product family should be developed or whether an existing product family should be adopted. As the result of this decision making process was to design a product family, the design process was then split into two parts. One part of the process focused on the development of the product family, and the other on the development of the WeRMST. The design of the WeRMST then continued with the determination of the number and configuration of workstations, the assignment of tasks to workstations, the selection of equipment, the design of the electronics and controls, and the implementation of the system ${ }^{14}$.

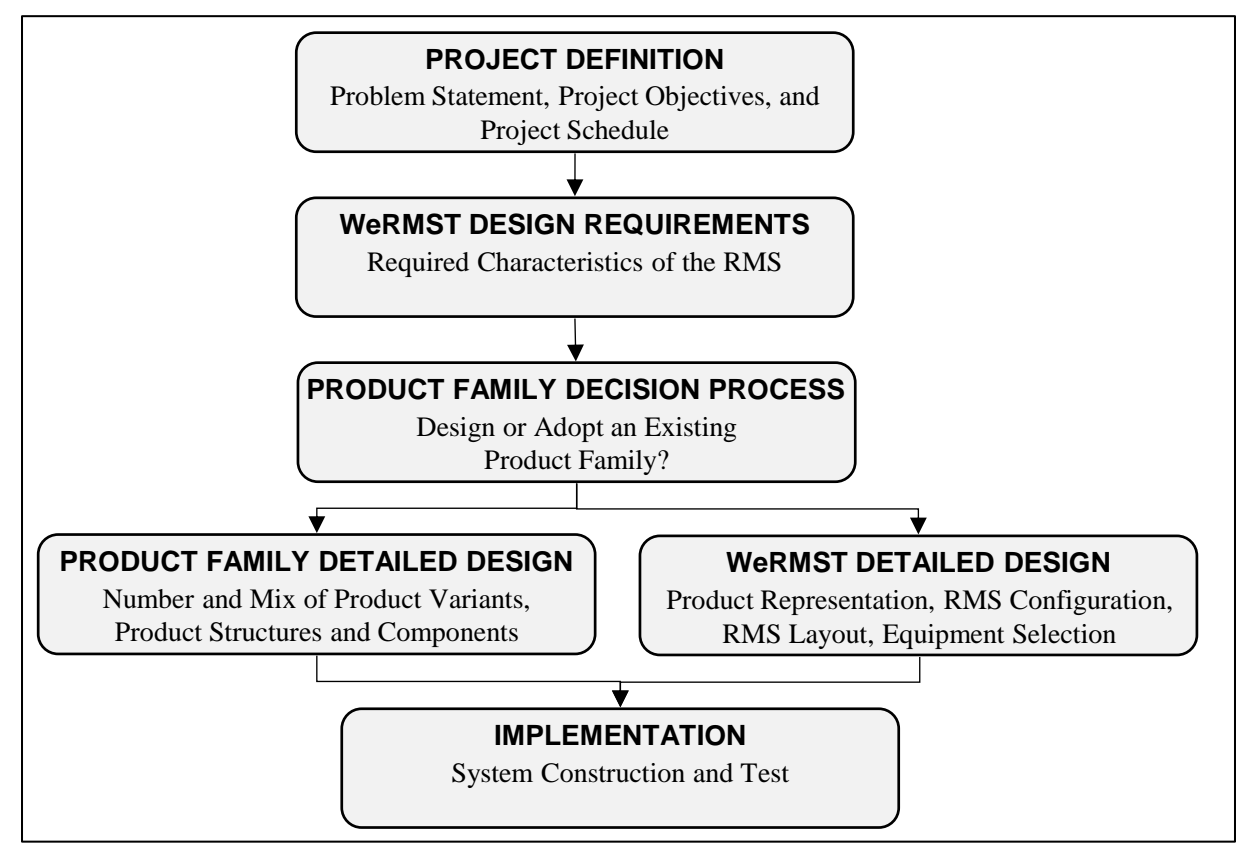

Fig. 1 WeRMST Development Process

\subsection{Project Definition}

The main purpose of the project was the development of the WeRMST to support the teaching of courses in manufacturing systems. As a result of the opportunity it provided, the plans for the system was extended to include research and industrial collaboration activities. Therefore, the specific project objectives of the project were the development of a RMS testbed to:

1. Support the teaching of manufacturing systems courses

2. Test research theories on manufacturing system design

3. Serve as a source for extra-curricular and co-curricular student projects

4. Serve as a platform for industrial collaborations

The main customers of the WeRMST were identified as the administration and students of the department in which the system was being developed. In addition, the system was funded 
entirely by the department. As a result, meetings were held with department's administrators to obtain support for the project, refine the project's requirements, and to identify a suitable a space for the development of the system.

\subsection{WeRMST Requirements}

A number of techniques were used to develop the requirements for the WeRMST. These included, brainstorming sessions among the project's team members, benchmarking of similar manufacturing system testbeds at other universities, and interviews with departmental administrators. As a result of these exercises, the list of ten requirements presented in Fig. 2 was developed. These project requirements included consideration of the type and performance of the technology that would be included on the system. In addition, three of the requirements, 1, 6, and 7 , ensured that the system would have the adaptability to be used for a wide range of future projects.

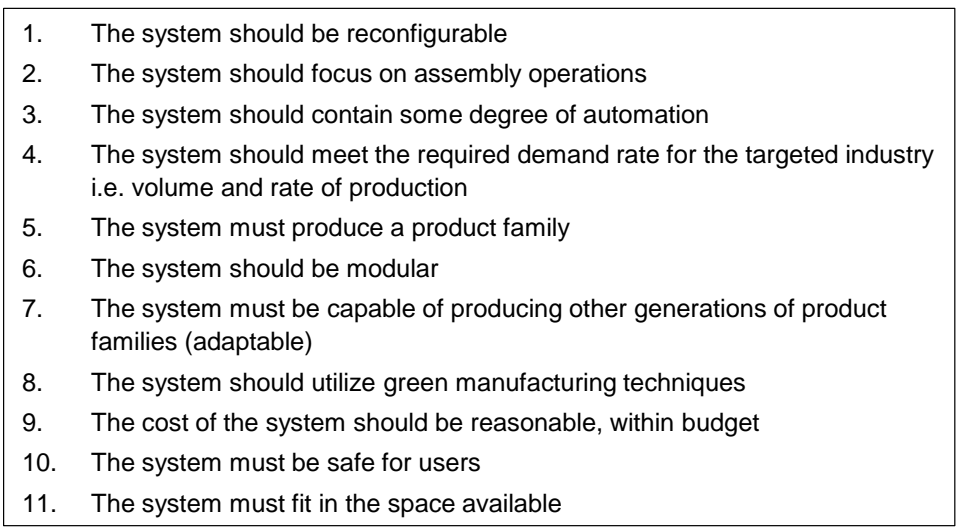

Fig. 2 WeRMST Requirements

\subsection{Product Family Decision Process}

Although the WeRMST was developed to support a yet unknown series of student and research projects, it would not have been possible to develop the system without consideration of a product as without a product, there is no need for an innovative manufacturing process or system. In fact, this focus on products is inherently important for the design of manufacturing systems ${ }^{1}$. Therefore, the design/or selection of a product for the WeRMST was an important part of the WeRMST development process. By basing the design of the WeRMST on the RMS characteristics of adaptability, convertibility, scalability, and reconfigurability, Fig. 2, the system, which was developed for one product family, could easily be reconfigured to produce other product families.

In product development, a product is typically given first, and the objective of the manufacturing system design process is to design a manufacturing system that could be used to manufacture the product. When developing the product family to be built on the WeRMST, the project team was faced with the inverse problem. The requirements for the WeRMST were given and the objective of the product family design/selection process was to obtain a suitable product family that will 
satisfy the requirements of the WeRMST. In order to accomplish this, the team used the following procedure:

\section{Product Family Requirements}

A set of requirements for the Product Family was generated.

\section{Check of Product Family Requirements}

The product family requirements were checked against the requirements of the WeRMST to ensure that there was consistency between the both.

\section{Potential Product Categories}

A list of possible ideas for products was generated.

\section{Product Category Selection}

A Pugh Chart was used to select the product category that best met the requirements for the WeRMST

\section{Design vs Adopt the Product Family}

A decision making process was used to determine whether a suitable product family in the selected product category already existed on the market, or whether a new product family had to be designed for the WeRMST.

The team worked together to generate the requirements for the product family. The ten product family requirements that were found to be consistent with the requirements for the WeRMST given Fig. 2 are presented in the left column of the Pugh Decision Matrix in Table 1. Next, each of the four team members generated three ideas for product categories resulting in a total of twelve ideas, ten of which were unique. The list of suggested products included lamps, ladders, carts, corkscrews, multi-tools, tripods, pencils, bicycles, toy cars/vans, and blocks. As a result of the wide range of suggested product categories, a two-step decision process was used to select the most appropriate product family. In the first step, each team member voted for the three products that, in their estimation, best met the requirements of the WeRMST. The four products receiving the highest number of votes were lamps, multi-tools, tripods, and ladders. The second step of the decision process involved the use of the Pugh Chart shown in Table 1 to select the product category that best met the requirements for the product family given in Step 1. From Table 1, it is observed that the product family of lamps best meet the product family requirements given in Step 1. Therefore, a market search was conducted to find an appropriate product family of lamps. Finding none, the team decided to develop its own product family of lamps. The design of the product family of lamps then proceeded concurrently with the design of the WeRMST as shown in Fig. 1. Additional details about the development of the product family are provided in another paper ${ }^{15}$. 
Table 1 Pugh Decision Matrix for Product Category Selection

\begin{tabular}{|c|c|c|c|c|c|c|}
\hline & CRITERIA & WEIGHTS & LAMPS & MULTI-TOOLS & TRIPODS & LADDERS \\
\hline 1 & Materials & 2 & 8 & 2 & 6 & 6 \\
\hline 2 & Assembly Operations & 4 & 8 & 2 & 4 & 8 \\
\hline 3 & Modular Design & 4 & 6 & 6 & 6 & 8 \\
\hline 4 & Changeable/Updatable & 2 & 8 & 4 & 6 & 8 \\
\hline 5 & Green & 1 & 6 & 6 & 4 & 2 \\
\hline 6 & Cost Effective & 2 & 8 & 2 & 4 & 6 \\
\hline 7 & Components easily manipulated by robots & 2 & 6 & 8 & 4 & 4 \\
\hline 8 & Aesthetically Pleasing & 1 & 8 & 6 & 6 & 4 \\
\hline 9 & Size should be appropriate & 2 & 8 & 8 & 6 & 4 \\
\hline \multirow[t]{2}{*}{10} & Type of Product Family Differentiation & 2 & 6 & 6 & 4 & 4 \\
\hline & & Total & 160 & 104 & 110 & 134 \\
\hline
\end{tabular}

\subsection{WeRMST Development}

The detailed design of the WeRMST began as soon as the conceptual design of the product family of lamps was known. Figure 3 shows the procedure that was used to develop the WeRMST. The procedure consisted of two main steps: (1) System Level Design, which occurred concurrently with, (2) Station Level Design.

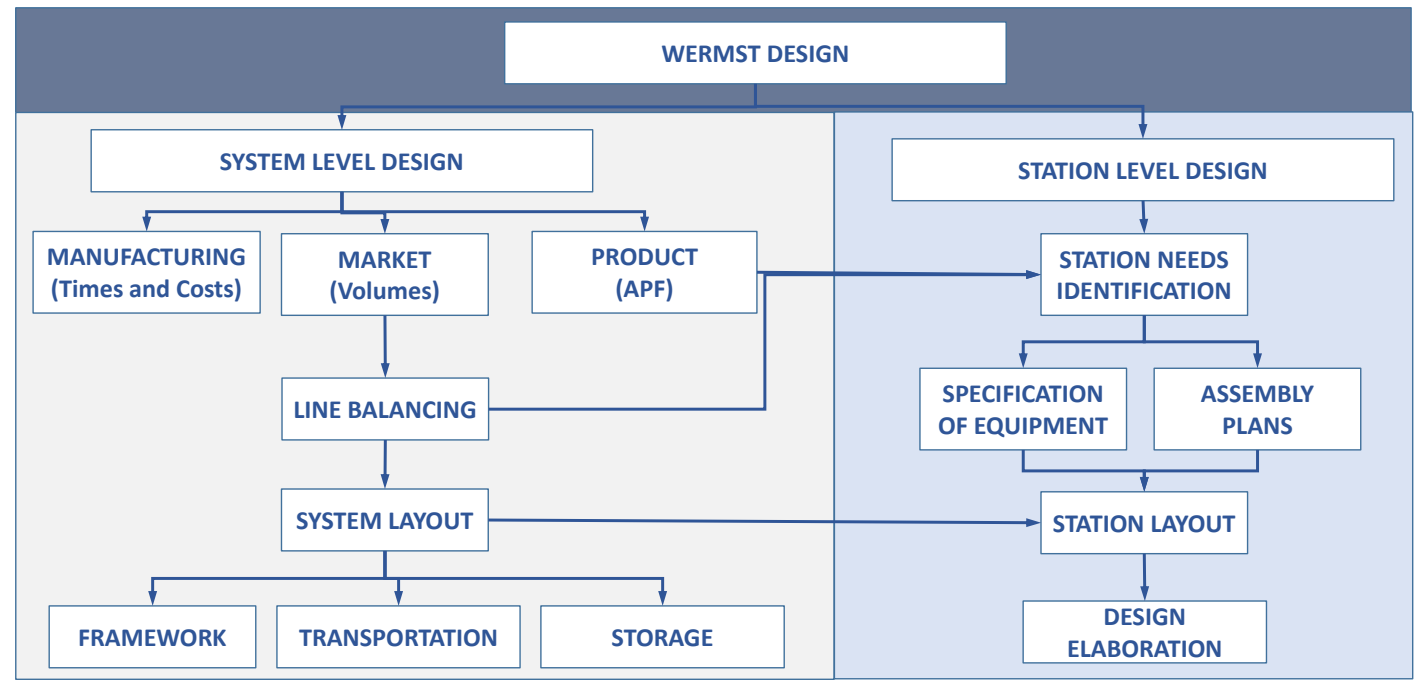

Fig. 3 WeRMST Design Procedure

The procedure for System Level Design began with the development of representations for the product family. Figure 4 shows that the product family of lamps consisted of three product variants with a total of twelve modules. All, except the first module, were differentiating modules. Therefore, the adopted representations were the architecture of the product family $(\mathrm{APF})^{12}$ and the mixed model product family precedence diagram ${ }^{10}$. The next step of System Level Design involved the use of mixed product assembly line balancing (MPALB) ${ }^{10-11,13}$ to determine the number and arrangement of workstations, and the assignment of tasks to workstations. As design for scalability was considered, MPALB was performed for a range of cycle times between $60-180$ seconds. The line balancing results were then consolidated to generate the assignment of tasks to workstations for scalability given in Fig. 5. After MPALB, 
the system was laid out in the allocated space to determine the appropriate sizes and geometries of the workstations. Detailed design of the system followed the conceptual design of the system layout. This involved the selection of appropriate materials, equipment, and storage for the workstations. It also involved the selection of a system transportation method and a method for transporting parts from the main system to the workstations and vice versa.

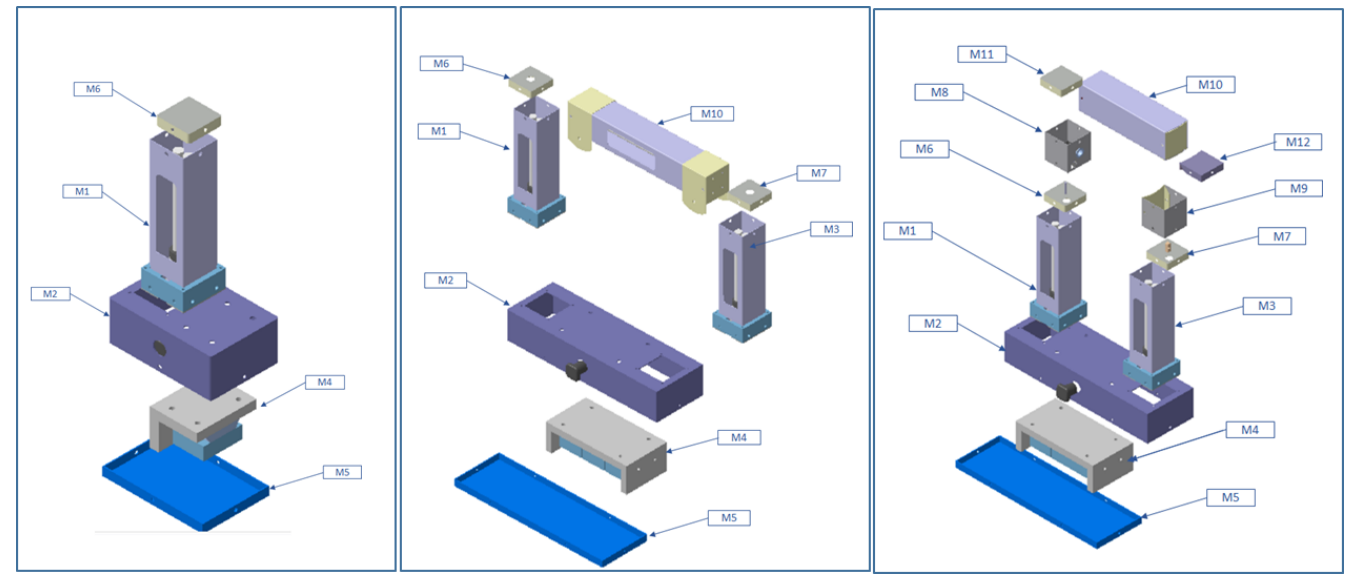

Fig. 4 Product Family of Lamps

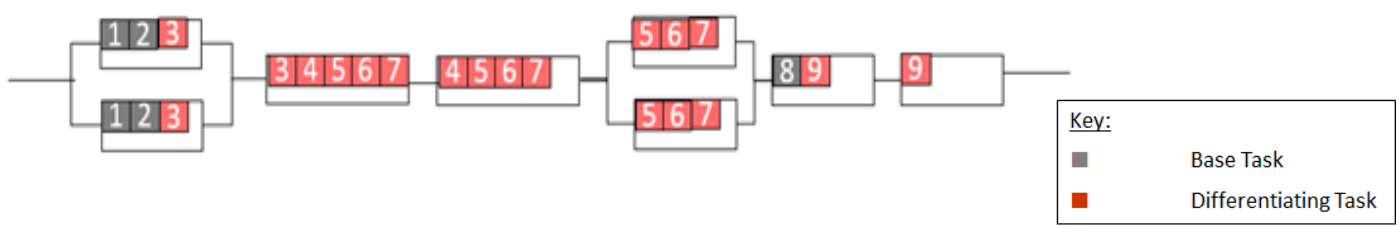

Fig. 5 MPALB Results for Scalability

As a result of cost, safety and availability, it was decided that a conveyor would be used for transporting components among workstations and robots would be used for transporting components from the conveyor to the workstations. Using the conveyor as a constraint, five candidate layouts were generated to fit within the space assigned by the department. As a result of its low cost, ease of assembly and disassembly, durability, and aesthetic appeal, aluminum extrusion was selected as the material of choice for building the system framework. Since the development of the fully designed WeRMST with the $60 \mathrm{sec}$ cycle time was predicted to be too costly at this stage of the project, a decision was made to develop the initial WeRMST for the slowest cycle time of $180 \mathrm{sec}$.

As shown in Fig. 3, the design of each workstation proceeded simultaneously with the design of the overall system. Once tasks were assigned to workstations, appropriate equipment and fixtures for accomplishing the tasks were selected. The selected equipment, workstation transportation mechanism, and workstation storage areas were then arranged to fit within the constraints set by 
the system. The iterative design at the system level and workstation level continued until a system that fit within the project budget and space was developed.

The technologies considered for assembling the components of the product family included screw driving machines, riveting machines, and spot welding machines. The team conducted a market search to determine the cost, sizes, rate of production, and lead time of the equipment available on the market. Of the three assembly methods considered, only screw driving machines met the team's budget and schedule requirements. Therefore, this assembly method was adopted. Since it would not have been possible to complete two of the assembly tasks shown in Fig. 4 with a screw driving machine, these tasks were designed to be completed manually.

\section{Description of the Reconfigurable Manufacturing System}

\subsection{Design of the Physical WeRMST}

This final design of the WeRMST is presented Figs. 6-7. The figures show that the system has a parallel-serial configuration with six workstations and eight centers. Workstations 1 and 6 each have two parallel centers, while the remaining four workstations have one center each. In order to meet the $180 \mathrm{sec}$ cycle time, tasks are only assigned to Workstations, 1, 4, and 6, with the utilization of just one center at each of these workstations. The other stations would remain unused for this initial implementation. All utilized workstations have the capability for automatic screw driving and Workstation 4 has the capability for manual assembly operations as well. Two storage stations, which are shown in Fig, 7 but not in Fig. 6, are placed at the start and the end of the manufacturing system.

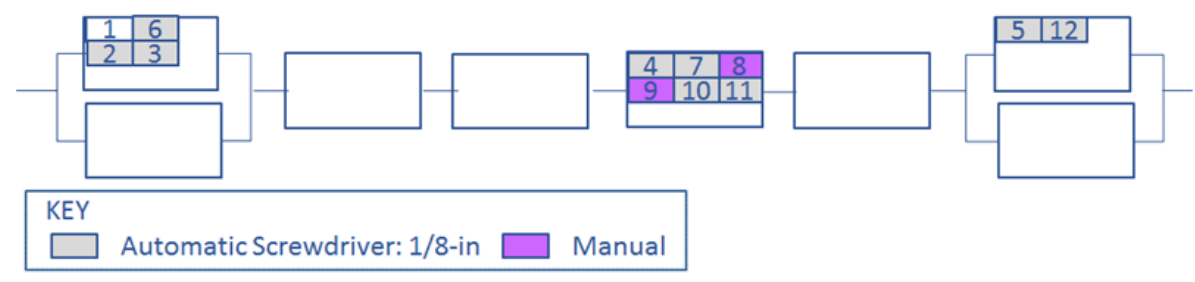

Fig. 6 Final Design of the WeRMST

Figure 7 shows that all centers are modular and identical in size. The workstations themselves are staggered on either side of the conveyor belt to fit the configuration of the room. In order to meet the $180 \mathrm{sec}$ cycle time, the conveyor belt is designed to run at a speed of $1 \mathrm{fpm}$. Not only are the sizes of the centers identical, but the layout of fixtures, storage, robot, and gantry at each center is similar. The differences among the centers reside in the detailed design of fixtures for completing subassembly and component assembly operations, the configuration of storage areas for allowing access to components, the grippers that are attached to robots for work holding, and the equipment that is attached to the gantry for assembly. 


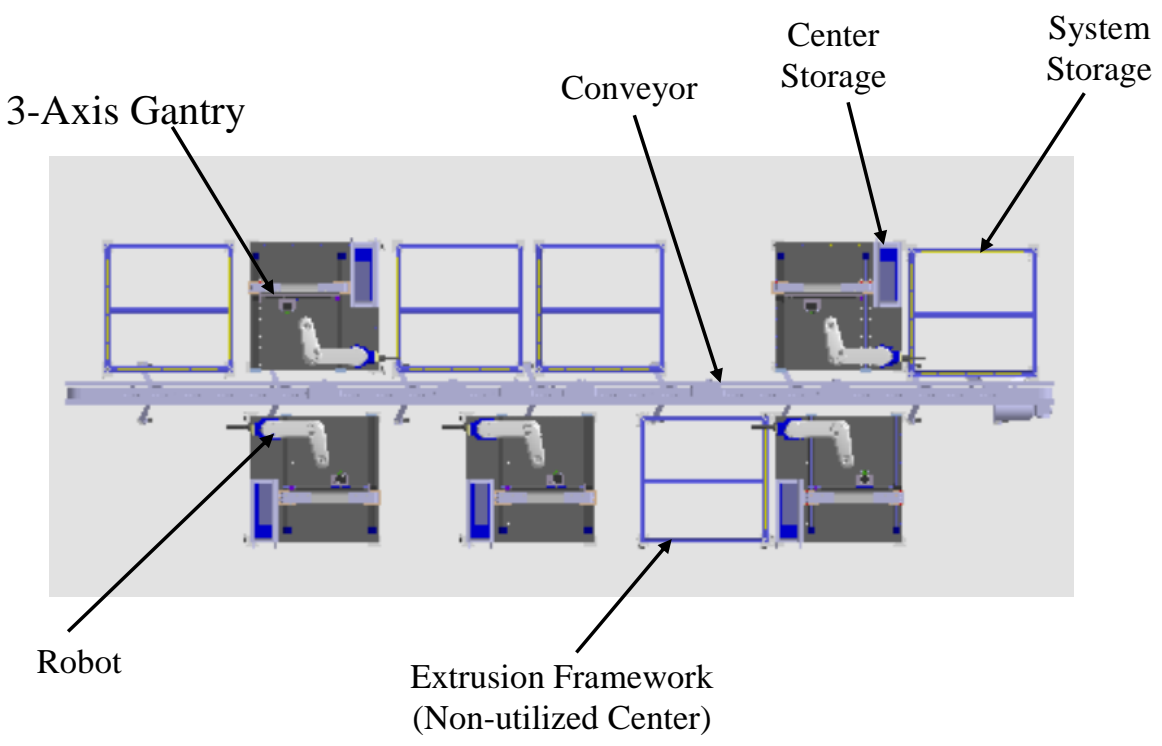

Fig. 7 CAD Model of the Designed WeRMST

\subsection{Design of the Control and Electrical Architecture of the WeRMST}

The design of the software and controls of the WeRMST followed the same basic principles as the design of the physical system. Notably, the control and electronics architectures were designed to be reconfigurable, modular, automation-focused, adaptable, low-cost, and suitable for educational laboratories, Fig. 2. A key consideration for the design of any assembly control architecture is the choice between distributed or centralized control ${ }^{16}$. The WeRMST requirements for reconfigurability, modularity, and adaptability eliminated the possibility of using pure centralized control from practical consideration. Instead, a simple and finite connectivity scheme was determined to be essential for meeting the WeRMST requirements. However, a certain amount of central control was still important for maintaining an efficient human interface to the system for configuration specification. As result, a pure distributed agentbased control architecture was also determined to be insufficient for meeting the WeRMST requirements.

The control architecture of the WeRMST consists of a master controller that is connected to a controller on each workstation via a data bus as shown in Fig. 8. Nearly every component of the system is reconfigurable and modular. Modules in Fig. 8 are identified as color-coded groups. The Central Controller of the WeRMST was designed to translate a sequence of commands which define the sequential operation of the system. These translated commands can then be communicated to each workstation controller which implements command sequences resident on each of the individual workstations (distributed control). Calibration, control of electromechanical components, sensing (including safety elements), and manual overrides were all designed to be handled at the station level and the implementation of these operations were designed to be isolated from the central controller. This approach minimizes the complexity of changing a workstation component or implementation. Each workstation controller also includes a display output which shows the status of the workstation, such as the $\mathrm{X} / \mathrm{Y} / \mathrm{Z}$ position for a 
gantry. Additionally, each workstation includes a manual control input to easily find position setpoints.

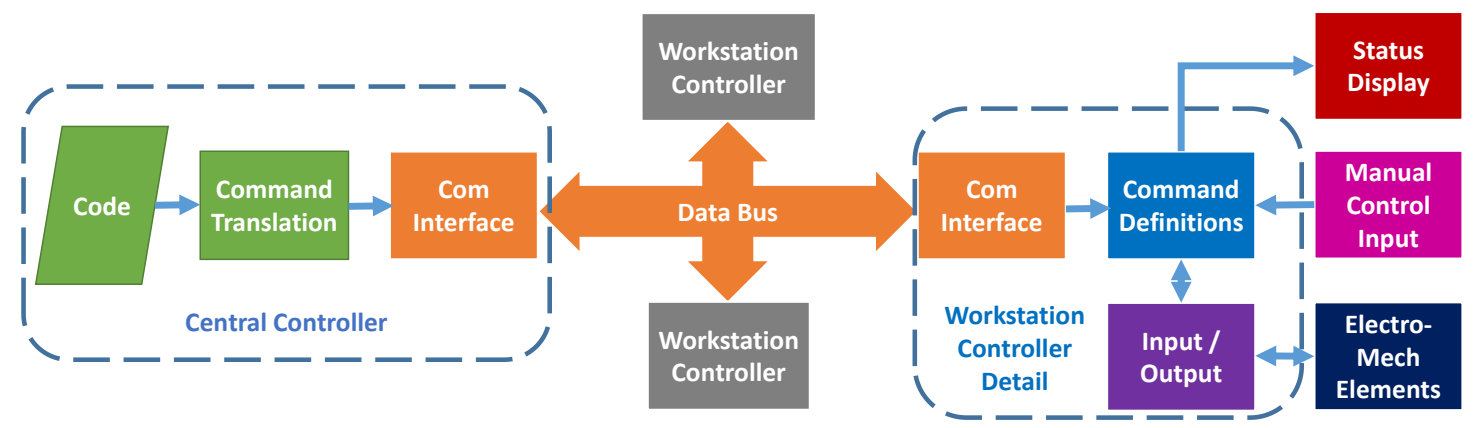

Fig. 8 WeRMST Control Architecture

To improve reconfigurability and minimize costs, the central and station controllers were designed to be microcontroller-based and to avoid optical isolation of inputs and outputs, which are common for PLC-based control systems. This is advantageous for the WeRMST application due to the flexibility provided to reconfigure I/O connections as inputs, outputs, pull-up/down inputs, tri-state outputs, etc. via software-only modifications. Figure 9 shows the current implementation of the workstation control modules.

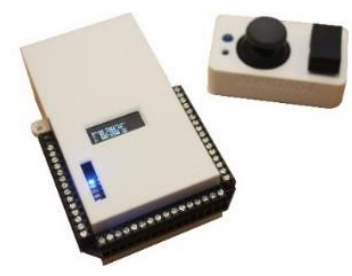

Fig. 9 Workstation Control Modules

\subsection{Reconfigurability of the Physical WeRMST}

Although the initial system described in this paper has the capability to produce a product family of lamps using screw driving and manual operations, the system has several features that allow for quick and easy changeover to the production of alternative product families. Firstly, the system layout is reconfigurable and can easily meet the needs of a range of line balancing solutions. In addition, the individual workstations are reconfigurable and can be quickly and easily changed to produce the features of an alternative product family.

The main features that allow for quick changeover of the system include: (1) The modularity and transportability of centers and (2) The modularity of the conveyor. All centers are constructed from identical alumimum extrusions, allowing for the same availability of space and interfaces 
with the conveyor. This, along with the light weight of the aluminium framework, and use of wheels, allows for ease of repositioning of the centers. Although the conveyor shown in Fig. 7 appears to be continuous, its framework consists of height adjustable, wheel-mounted, modular sections that have been sized to be consistent with the centers. The belt is made of links that can easily be added and removed. Finally, a variable frequency drive, VFD, is attached to the fixed speed motor of the conveyor allowing for adjustment of the rate of transportation of the product through the system.

As for the system, there are a range of features that allow for reconfigurability in the workstations. Each center has an identical layout that consists of an assembly area that includes a three-axis gantry and fixtures, a storage area, and a six-axis robot. The three-axis gantry is equipped with generic adapter plates, electronics and gas-supply lines that allow for ease of addition and removal of different types of electrical and pneumatic assembly tools such as screwdriving, spot-welding, and riveting machines. Therefore, as more funding becomes available, the initial screw driving machines can be changed to other types of assembly equipment. The open area under the gantry allows for fixtures of various designs and sizes to be positioned under the equipment in the most favourable orientation for assembly. The open-architecture of the storage area facilities ease of access to components of various shapes and sizes. The robot is positioned so as to allow ease of access to the assembly area, storage, and conveyor system. In addition, it has interfaces that allow for the connection of different types of grippers.

\subsection{Reconfigurability of the Software and Controls of the WeRMST}

The workstations of the WeRMST share a common communication bus, and each workstation is addressable by the central controller. As a result, the addition or removal of workstations can be handled at the control system level by simply adding or removing addressed commands in the command sequence, Fig. 8. The modularity of the WeRMST control architecture means that nearly every aspect of the control system may be reconfigured without modifications to any other system components. For instance, if it is desirable to replace a data/address bus communication scheme with an $\mathrm{I}^{2} \mathrm{C}$ communication scheme, only the communications interface software modules would need to be replaced on the central and workstation controllers. No hardware replacement would be necessary due to the reconfigurable microcontroller-based I/O.

Where hardware reconfigurations are necessary, the workstation controllers can be easily reconfigured using stackable hardware "shields." For instance, if the ability to drive a $24 \mathrm{~V}$ input is necessary to communicate with a certain motor controller, a stackable shield may be added which boosts the $5 \mathrm{~V}$ output signal of the station controller to a $24 \mathrm{~V}$ signal, with the motor controller connected directly to this shield. Software command and control is also easy to reconfigure with the WeRMST, and affords the user as large amount of flexibility in determining the degree to which a distributed design is implemented. Users may implement very detailed command and control routines resident on workstation controllers for pure distributed control, or may rely on simpler commands implemented on the workstation controller and a more detailed command sequence on the central controller. A summary of reconfiguration methods for each component of the WeRMST control architecture is provided in Table 2. 
Table 2 Reconfiguration methods for the WeRMST control system and associated electronics

\begin{tabular}{|l|l|}
\hline \multicolumn{1}{|c|}{ Component } & \multicolumn{1}{c|}{ Reconfiguration Methods } \\
\hline $\begin{array}{l}\text { Command } \\
\text { Language }\end{array}$ & Replace command translation module \\
\hline $\begin{array}{l}\text { Communication } \\
\text { Interface }\end{array}$ & Replace communication interface definition \\
\hline $\begin{array}{l}\text { Command } \\
\text { Definitions }\end{array}$ & $\begin{array}{l}\text { Add additional command-handling subroutines to the } \\
\text { station controller }\end{array}$ \\
\hline Input/Output & $\begin{array}{l}\text { Modify command-handling subroutines or add stackable } \\
\text { electronics "shield" for physical signal translation }\end{array}$ \\
\hline Display & Replace display module \\
\hline Manual Controller & Replace controller module \\
\hline $\begin{array}{l}\text { Electromechanical } \\
\text { Components }\end{array}$ & $\begin{array}{l}\text { Reconfiguration depends on the nature of the } \\
\text { modification and may be limited to replacing a controller } \\
\text { or possibly include replacing command-handling } \\
\text { subroutines and/or interface modification (see } \\
\text { "Input/Output"). }\end{array}$ \\
\hline Station & $\begin{array}{l}\text { Add/remove/modify commands and command addresses } \\
\text { in the central controller code }\end{array}$ \\
\hline
\end{tabular}

\section{Description of the Manufacturing System Design Course}

The proposed course to be supported by the WeRMST is a traditional manufacturing systems course that includes topics focused on the analysis and modelling of manufacturing systems. Specific topics to be covered in the course include product family representations using liaison and precedence diagrams, methods of assembly, approaches to manufacturing i.e. push vs pull, mass-production to personalized production, design and analysis of manufacturing lines and configurations including line balancing, and productivity analyses. It is traditional to teach these topics using a lecture format. However, the use of innovative active learning strategies, such as Flipped Classroom methodologies is also possible.

For this course, traditional technical activities would be supplemented by opportunities for students to experiment with various aspects of the WeRMST as it is through this process the cognitive abilities of students could be developed. The labs will focus on the details of implementation of the techniques taught such as the effect of fixture designs and orientation of assembly equipment on the ease of assembly. In addition, system level concepts such as the effect of various task-workstation assignments on system productivity would be implemented on the WeRMST.

A team-based term project would be used to bring together all the manufacturing system concepts taught in the course. The novel aspect of this project would be the opportunity that students will have to demonstrate a working prototype of their manufacturing system designs on the WeRMST, in much the same way as is done in product design courses. It is hoped that this approach will motivate students to develop more realistic manufacturing system designs. 


\section{Assessment of the Impact of the WeRMST}

\subsection{Potential Impact}

The procedure that was utilized for the development of the WeRMST is a practical solution for the acquisition of a manufacturing systems lab in a university environment, within relatively small budget and space constraints. The development cost of the system presented in this paper was approximately $\$ 60 \mathrm{~K}$, which is much lower than that of an off-the shelf solution. As the WeRMST was developed within a university, utilizing the knowledge of members of staff, its hardware and software maintenance costs are also expected to be significantly lower than that of an off-the-shelf solution.

The WeRMST also provides advantages over existing pedagogical approaches such as factorybased projects and simulations. Although the WeRMST was developed for a university environment, its realistic design makes it suitable for industrial projects. In fact, this system may make it more convenient and attractive for industrial partners to work with the university as it provides a platform for industrial collaborations without the need for interrupting production at the factory. The WeRMST is more realistic than simulations and it allows for the development of a wide range of alternative systems. One potential drawback of the system is that it may not allow for the testing of as many alternative scenarios as simulations would. However, a combination of the two approaches, may be the best approach for developing students' theoretical and practical skills.

The benefits of the WeRMST can potentially extend beyond its use in the manufacturing systems course for which it was developed. The WeRMST was built with a combination of mechanical, electrical, and software components, on an adaptable, reconfigurable, and scalable platform. These components are useful for various types of engineering designs and applicable to a wide range of fields. Therefore, the WeRMST can potentially be used to teach other courses such as machine design, circuit design, automation, robotics and controls.

The greatest potential impact of the WeRMST is expected to be with the students. Students tend to be more engaged and motivated in courses that include practical activities such as these. A highly engaged student body is expected to help with student retention and can serve as a motivator for new students to join the program. In addition, it will provide students with an opportunity to gain a deeper understanding of the impact of their manufacturing system design decisions in a non-threatening environment.

\subsection{Impact of the WeRMST to Date}

Although it is relatively new, the WeRMST has already yielded some benefits. These include: (1) A change in curriculum, (2) An undergraduate research project, and (3) An interdisciplinary collaboration.

At the time the WeRMST was being developed, the manufacturing engineering program in the department in which it was developed did not have an existing course in manufacturing systems. The course described in Section 4 was merely a proposal. As a result of the successful 
development of the WeRMST, an experimental course has been established as an elective. If successful in its first few offerings, the course will become a permanent part of the program's curriculum.

The WeRMST was developed by five undergraduate student researchers, Fig. 10. Three students were involved in the initial planning and specification of the system. The remainder of the project was completed by four students. Two of these students focused solely on the design of the product family, one student focused on a mix of product family design and station level design issues, and one student focused on the system level design of the WeRMST and the concurrent design of the product family and assembly system. In order to ensure the successful completion of the project, all the students needed to work closely together.

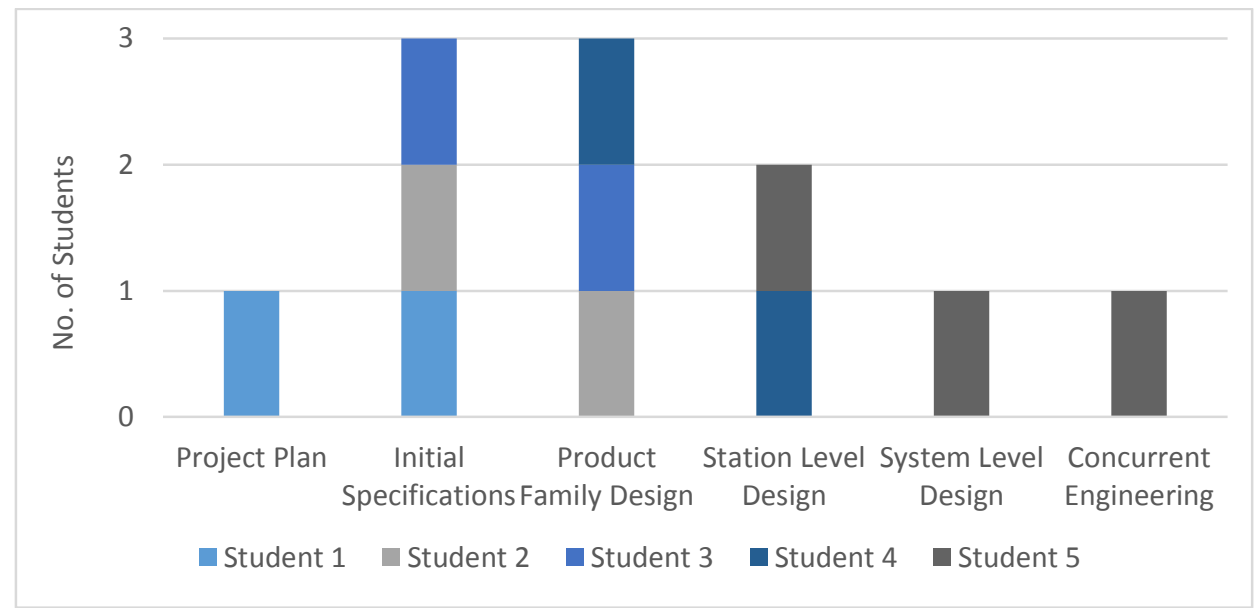

Fig. 10 WeRMST Student Design Team

A questionnaire was sent to the team of student researchers at the conclusion of the project. Four out of the five students responded. The results are presented in Fig. 11. On a question to determine the technical knowledge that was gained through the project, the top five responses indicate that as a result of this project almost all students learned about (1) manufacturing systems and processes, (2) product family design, (3) concurrent engineering, and (4) how manufacturing and product design decisions affect each other. On another question to determine the benefits that were gained through participating in the project, two out of four of the students indicated the development of teamwork skills, and two out of four students indicated learning to work with suppliers. Therefore, it can be seen that the RMS project was not only useful for helping the undergraduate student researchers to gain technical knowledge and experience, but it assisted them with the development of professional practice skills. 


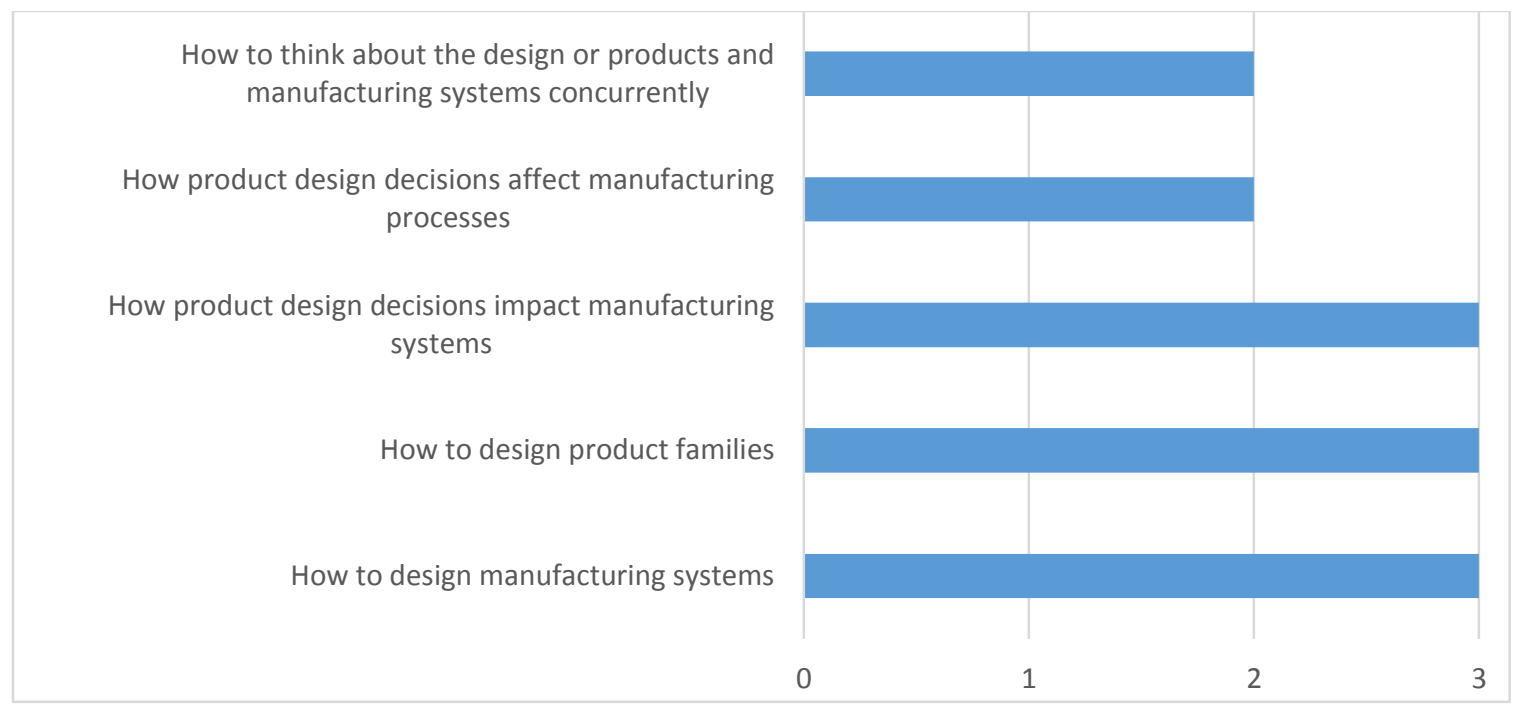

Fig. 11 Survey Responses to Question about the Technical Knowledge Acquired through Participation in the WeRMST Project

The WeRMST was initially developed by a professor in manufacturing engineering. However, as a result of the need to operationalize the electromechanical components of the system, a professor in electrical engineering joined the project. Therefore, through this project, an interdisciplinary collaboration was formed. This is only the second such collaboration in the department. This collaboration has already resulted in the development of a joint grant. Additional plans are in place for the development of interdisciplinary courses and additional research projects that are focused on the WeRMST.

Therefore, even at this infant stage, the WeRMST has yielded several benefits. The main benefit of the WeRMST has been the creation of a platform for research for the students and faculty collaborators. The benefits will extend to the department and a bigger population of students when the course on manufacturing system design is implemented. As familiarity with the system grows, additional faculty from other programs will be invited to participate and the system will be applied to a wider range of courses.

\section{Conclusion}

This paper presented the development of the WeRMST, which is a RMS testbed that was developed for supporting a manufacturing systems course. For this course, the WeRMST would be used to teach physical labs on assembly, as well as for the demonstration of student term projects. As a result, the WeRMST would be useful for providing students with a means for making connections between the theories that they learn in lectures with the practice of manufacturing system design. Other intended uses of the WeRMST are as a platform for testing research theories on manufacturing systems, as a source of undergraduate curricular and cocurricular projects, and as a platform for industrial collaborations. 
This initial system, which was developed entirely by the faculty, students, and staff, was designed to produce a product family of lamps using assembly operations. However, as the system architecture, stations, and control architecture of the WeRMST were designed along the principles of RMS, the design can easily be reconfigured to produce other product families. In addition to its reconfigurability, the development costs were relatively small when compared to that of an off-the-shelf system and the maintenance costs are expected to be relatively small as well.

The WeRMST has already yielded benefits for the department in which it was developed. It has resulted in the implementation of a new course in manufacturing systems, served as a source for an undergraduate research projects, and has led to the establishment of an interdisciplinary faculty research collaboration. It is expected to yield additional benefits such as the development of interdisciplinary courses, additional interdisciplinary research projects, and industrial collaborations in the areas of manufacturing systems, automations, and controls.

\section{References}

[1] Waldorf, D., Alptekin, S. E., \& Bjurman, R. (2006). Plotting a bright future for manufacturing education: results of a brainstorming session. Industrial and Manufacturing Engineering, 4.

[2] Dessouky, M. M., Verma, S., Bailey, D. E., \& Rickel, J. (2001). A methodology for developing a web-based factory simulator for manufacturing education. IIE transactions, 33(3), 167-180.

[3] Todd, R. H., Red, W. E., Magleby, S. P., \& Coe, S. (2001). Manufacturing: A strategic opportunity for engineering education. Journal of Engineering Education, 90(3), 397-405.

[4] Dutta, D., Geister, D., and Tryggvason, G. (2004). Introducing hands-on experiences in design and manufacturing education. International Journal of Engineering Education, 20(5), 754-763.

[5] Lamancusa, J. S., Jorgensen, J. E., \& Zayas-Castro, J. L. (1997). The learning factory-A new approach to integrating design and manufacturing into the engineering curriculum. Journal of Engineering Education, 86(2), 103-112.

[6] Seemakula, M. E.. (2002). Introducing hands-on manufacturing experience to students. Proceedings of the ASEE Annual Conference, Montreal, Canada, 16-19 June.

[7] Jara, C. A., Candelas, F. A., Puente, S. T., \& Torres, F. (2011). Hands-on experiences of undergraduate students in Automatics and Robotics using a virtual and remote laboratory. Computers \& Education, 57(4), 24512461.

[8] Rentzos, L., Doukas, M., Mavrikios, D., Mourtzis, D., \& Chryssolouris, G. (2014). Integrating manufacturing education with industrial practice using teaching factory paradigm: A Construction Equipment Application. Procedia CIRP, 17, 189-194.

[9] Koren, Y., Heisel, U., Jovane, F., Moriwaki, T., Pritschow, G., Ulsoy, G., and Van Brussel, H. (1999). Reconfigurable manufacturing systems. CIRP Annals - Manufacturing Technology, 48(2), 527-540.

[10] Bryan, A., Wang, H., \& Abell, J. (2013). Concurrent Design of Product Families and Reconfigurable Assembly Systems. Journal of Mechanical Design, 135(5), 051001. 
[11] Bryan, A., Hu, S. J., \& Koren, Y. (2007). Concurrent design of product families and assembly systems. Proceedings of the ASME Manufacturing Science and Engineering Conference, Ann Arbor, MI, USA,15-18 October.

[12] Jiao, J., \& Tseng, M. M. (1999). A methodology of developing product family architecture for mass customization. Journal of Intelligent Manufacturing,10(1), 3-20.

[13] Rekiek, B., De Lit, P., and Delchambre, A., 2000, "Designing Mixed-Product Assembly Lines," IEEE Transactions on Robotics and Automation, 16(3), pp. 268-280.

[14] Askin, R. G., \& Standridge, C. R. (1993). Modeling and analysis of manufacturing systems. Wiley, NY, USA.

[15] Bryan, A., \& Lund, J. (2016). Design of Product Families for Reconfigurable Assembly Systems: Student Research Experiences. Proceedings of the ASEE Annual Conference, New Orleans, LA, USA, 26-29, June.

[16] Meng, F., Tan, D., \& Wang, Y. (2006). Development of Agent for Reconfigurable Assembly System with JADE. Intelligent Control and Automation, 2006. WCICA 2006. The Sixth World Congress on Intelligent Control and Automation, 2, 7915-7919. 